\title{
Phyllodes tumor of the breast
}

INSERM

\section{Source}

INSERM. (1999). Orphanet: an online rare disease and orphan drug data base. Phyllodes tumor of the breast. ORPHA:180261

Phyllode tumor of the breast is a rare fibroepithelial neoplasm accounting for less than $1 \%$ of all mammary tumors, usually presenting in adult females (most frequently between the ages of 35-55 years), ranging from benign to malignant and often presenting with well circumscribed mobile masses that grow rapidly and sometimes with additional non-specific symptoms such as dilated skin veins, nipple retraction, skin ulcers, palpable axillary lymphadenopathy or blue discoloration of the skin. 